\title{
Pesquisa clínica conduzida por estudantes de medicina: SeU POTENCIAL PARA $O$ aprendizado e para a PRODUÇäo CIENTífICA NACIONAL
}

A iniciação científica no nível de graduação geralmente consiste na participação de um aluno do curso médico em um projeto de pesquisa em andamento conduzido por um docente. Usualmente, o aluno, através da orientação deste docente, pleiteia uma bolsa de iniciação à pesquisa junto a uma fonte de fomento como, por exemplo, FAPESP (no caso de São Paulo) ou CNPQ que, se outorgada, passa, além de the prover uma contribuição financeira mensal, a requerer relatórios periódicos do andamento de seu projeto, bem como da apreciação do docente que the orienta acerca de seu desempenho. Para termos uma idéia quantitativa, ainda que grosseira, da situação da iniciação à pesquisa no Brasil, analisemos em linhas gerais a situação do Estado de São Paulo, responsável por cerca de um terço das escolas médicas do País, isto é, 26 escolas médicas e cerca de 13.000 alunos de medicina. A FAPESP, em 2004, forneceu cerca de 300 bolsas e o CNPQ cerca de 2400 bolsas de iniciação à pesquisa para a área de saúde para o estado paulista. Se considerarmos que apenas uma fração destas bolsas foi outorgada para estudantes de medicina, veremos que provavelmente menos do que 10\% destes alunos recebem uma bolsa de iniciação ao longo do seu curso médico. Este modelo, entretanto, tem suas limitações, pois é restrito a uma minoria de alunos que podem contar em suas respectivas escolas de medicina com a presença de investigadores produtivos e experientes; geralmente, o aluno não participa da idealização do projeto no qual vai participar, apenas aderindo a ele quando este já se encontra em andamento dentro de uma linha de pesquisa do orientador e, finalmente, por ser esta uma atividade de cunho extracurricular, há crescente dificuldade, à medida que o aluno progride no curso médico, de se dedicar a ela pelo envolvimento em plantões e outras atividades didático-assistenciais típicas do internato.

Uma outra possibilidade para que alunos de graduação se aproximem de atividades de pesquisa seria oferecê-las rotineiramente no contexto de uma atividade extracurricular muito difundida entre muitas escolas médicas do País: as ligas estudantis. Em nossa experiência na Faculdade de Medicina da Fundação $A B C$ (FMABC), nos últimos 10 anos desde a criação da Liga de Oncologia, denominada Sociedade Acadêmica de Estudo e controle do Câncer (SAECC), juntamente com os alunos envolvidos nesta atividade, criamos uma rotina de elaboração e execução de projetos de pesquisa que têm sido muito profícua. Além de atividades assistenciais semanais sob supervisão dos médicos assistentes do serviço em um ambulatório de oncologia geral especialmente designado para alunos, anualmente os alunos se dividem em quatro grupos e cada um destes elabora um projeto de pesquisa diferente sob orientação de um docente e assistên- cia de um monitor de pesquisa. $\mathrm{O}$ monitor de pesquisa é um aluno de quinto ou sexto ano, escolhido pelos próprios alunos consensualmente ao longo do ano, com pelo menos dois anos de experiência nas atividades científicas da SAECC e que se dedica a manter todos os projetos em adequado andamento. Este monitor recebe uma bolsa mensal da Associação de Voluntárias para o Combate do Câncer do $A B C$ (AVCC), uma entidade filantrópica que assessora pacientes oncológicos e nos apóia a desenvolver pesquisas sobre o câncer. Os estudos que conduzimos na SAECC são geralmente baseados em perguntas originais que surgiram quando da análise de dados de trabalhos conduzidos nos anos anteriores. Geralmente, privilegiamos trabalhos que envolvam questionários para aplicação em grupos de pacientes ou médicos e utilizados em 3 a 4 meses de trabalho de campo, que se inicia tão logo seja obtida a aprovação do projeto elaborado e escrito pelos estudantes juntamente com o docente pelo comitê de ética e pesquisa institucional. Após a coleta e análise dos dados (feitas pelos próprios alunos), cada grupo redige um manuscrito que é submetido para congressos e para publicação em periódicos nacionais ${ }^{-}$ ${ }^{4} \mathrm{e}$, algumas vezes também, internacionais ${ }^{5-7}$. Nossos estudantes aprendem assim a pesquisar a literatura, escrever projetos, se familiarizam com aspectos éticos relacionados à pesquisa clínica, lidam com coleta e análise estatística de dados, participam da elaboração de um manuscrito para publicação e também adquirem prática em apresentar oralmente e serem argüidos acerca de seus trabalhos em congressos médicos universitários ou de especialidades. $\bigcirc$ amadurecimento científico destes alunos é claro ao longo deste ciclo anual que pode, em alguns casos, se repetir 2 a 3 vezes durante o seu curso médico dentro da SAECC. Até o momento, 95 alunos passaram pela SAECC. Dos ex-membros avaliados, $89 \%$ permaneceram na SAECC dois ou mais anos, $70 \%$ acharam que as atividades desempenhadas na SAECC foram muito importantes para lhes ajudar a ler e 59\% para escrever artigos científicos. Apesar de apenas $11 \%$ dos exalunos terem seguido as especialidades de hematologia e/ou oncologia clínica, $77 \%$ deles e $84,61 \%$ dos atuais alunos classificaram a SAECC como a melhor das atividades extracurriculares em que se envolveram durante a faculdade. Portanto, se a pesquisa clínica se difundir através das ligas estudantis, conseguiremos envolver mais estudantes de medicina precocemente no seu curso médico, incluindo alguns de escolas com uma tradição de pesquisa ainda incipiente.

Acreditamos que o envolvimento dos alunos de medicina em atividades de pesquisa clínica tem um grande potencial 
didático de cultivar habilidades que Ihes serão úteis em qualquer especialidade que optem por seguir no futuro. Além das habilidades científicas já citadas, o aluno também vivencia um verdadeiro exercício de honestidade e humildade diante dos dados obtidos, especialmente quando estes contradizem uma ou mais de suas hipóteses iniciais. A pesquisa clínica pode, por conseguinte, melhorar a formação médica global do aluno que, no futuro, se defrontará com o experimento da natureza: cada doença que ele deverá diagnosticar e tratar.

Milene Nibi Abrão Carolina Games Bensi Marina Sahade Gonçalves

Juliana Lika Narahara

fabiana Celi Otsuka

Rodrigo Perez Ranzatti

Damila Cristina Trufelli Auro Del Giglio

REFERÊNCIAS

1. Samano ES, Goldenstein PT, Ribeiro LM, Lewin F, Filho ES, Soares HP, et al.

Praying correlates with higher quality of life: results from a survey on complementary/alternative medicine use among a group of Brazilian cancer patients. Sao Paulo Med J 2004; I 22(2):60-3.

2. Tucunduva LT, Sa VH, Koshimura ET, Prudente FV, Santos AF, Samano ES, et al. Evaluation of non-oncologist physician's knowledge and attitude towards cancer screening and preventive actions. Rev Assoc Med Bras 2004;50(3):25762

3.Moura AA, Lhano MG, Del Giglio A. Education via the Internet: preliminary experience of the hematology-oncology discipline of the $A B C$ Foundation School of Medicine. Rev Assoc Med Bras 2000;46(I):47-5I.

4. Uehara RP, Sa VH, Koshimura ET, Prudente FV, Tucunduva LT, Goncalves MS, et al. Continuous infusion of amphotericin B: preliminary experience at Faculdade de Medicina da Fundacao ABC. São Paulo Med J 2005 I ; 23(5):2 I 9-22.

5.Samano ES, Ribeiro LM, Campos AS, Lewin F, Filho ES, Goldenstein PT, et al. Use of complementary and alternative medicine by Brazilian oncologists. Eur J Cancer Care (Engl) 2005; | 4(2): | 43-8.

6.del GA, Soares HP, Caparroz C, Castro PC. Granisetron is equivalent to ondansetron for prophylaxis of chemotherapy-induced nausea and vomiting: results of a meta-analysis of randomized controlled trials. Cancer 2000;89(I I):2301-8.

7.Megale Costa LJ, Soares HP, Gaspar HA, Trujillo LG, Santi PX, Pereira RS, et al. Ratio between positive lymph nodes and total dissected axillaries lymph nodes as an independent prognostic factor for disease-free survival in patients with breast cancer. Am J Clin Oncol 2004;27(3):304-6. 